\title{
Um Modelo de Avaliação da Eficiência da Administração Pública através do Método Análise Envoltória de Dados (DEA)
}

A Model of Evaluation of the Efficiency of the Public Sector through the Method Data Envelopment Analysis (DEA) 


\title{
RESUMO
}

O objetivo deste trabalho é apresentar uma poderosa ferramenta, ainda pouco utilizada no Brasil, chamada Análise Envoltória de Dados (DEA). Esse Método pode ser utilizado para avaliar a eficiência técnica de unidades produtivas, que utilizam múltiplos insumos para produzir múltiplos bens e/ou serviços medidos em diferentes unidades. É recomendado no estudo da eficiência da administração pública, de instituições sem fins lucrativos e organizações, que operacionalizam suas atividades através de unidades como redes hoteleiras, franquias, unidades escolares, agências de correios e bancos. O Método compara os insumos e os produtos de cada unidade e determina os índices de eficiência relativa de cada unidade analisada. Estes índices permitem determinar as melhores práticas, as unidades ineficientes e as mudanças necessárias nos níveis de insumos e produtos para que as últimas unidades se tornem eficientes. Podem ser utilizados na identificação de recursos ociosos ou inutilizados e, na formulação de políticas de redução de custos, associada a uma expansão que otimize o potencial de crescimentos e o porte ideal do empreendimento; portanto é uma valiosa ferramenta para a pesquisa de benchmarking que permite o contínuo processo de aprimoramento.

Palavras-chave: avaliação; eficiência; análise envoltória de dados; administração pública.

\begin{abstract}
The objective of this work was to present a powerful tool, still little used in Brazil, called Data Envelopment Analysis (DEA). This Method can be used to evaluate the technical efficiency of productive units that use multiple inputs to produce multiple goods and services measured in different units. It is recommended in the study of the efficiency of the public administration, of institutions without lucrative purposes and organizations that accomplish your activities through units as hotel nets, franchises, school units, agencies of mail and banks. The Method compares the inputs and outputs of each unit and determines the index of relative efficiency of each analyzed unit. These indexes allow to determine the best practices, the inefficient units and the necessary changes in the levels of inputs and outputs, so that the last units become efficient. It can be used in the identification of idle resources or disabled and in the formulation of politics of reduction of costs associated to an expansion that optimizes the potential of growth and the ideal load of the enterprise. Therefore, it is a valuable tool for the benchmarking research that allows the continued improvement process.
\end{abstract}

Key words: evaluation; efficiency; data envelopment analysis; public administration. 


\section{INTRODUÇÃO}

Em todas as sociedades e em todos os setores, tanto públicos como privados, os recursos humanos e patrimoniais são escassos para atender às crescentes exigências dos clientes. Portanto, ao iniciar qualquer empreendimento e assim determinar que, como e quanto produzir, sempre os tomadores de decisões procuram a melhor combinação dos recursos e ainda buscam as formas mais racionais de organização da atividade econômica. Hoje, no desenvolvimento das atividades num entorno de crescente competitividade, a busca contínua de eficiência se torna um pré-requisito para a sobrevivência das organizações.

\section{EficiênCla: Definição e Quantificação}

A combinação ótima dos insumos e métodos necessários (inputs) no processo produtivo de modo que gerem o máximo de produto (output) é o que se conceitua como eficiência. Isto significa que a eficiência é a capacidade de fazer certo as coisas, de minimizar a relação insumos - produtos. Visa assegurar a otimização da utilização dos recursos e, portanto, relaciona-se com os meios e não com os fins.

A eficiência pode ser de dois tipos: eficiência técnica e eficiência econômica.

Um método de produção é eficiente do ponto de vista tecnológico, quando se emprega o menor nível de insumos possível para produzir um nível dado de produção, ou quando se obtém o maior nível de produção possível com um dado nível de insumo. Ou ainda, diz-se que um produtor, que produz dois ou mais produtos, é eficiente para certa quantidade de insumo, se ele somente conseguir aumentar a produção de um produto, quando diminuir a produção de algum outro.

Um método produtivo é mais eficiente do ponto de vista econômico que outro, quando o primeiro consegue uma quantidade de produto igual ao do segundo com menor custo, ou quando com o mesmo custo se obtém um nível de produção maior. A eficiência econômica é uma extensão da eficiência técnica, uma vez que envolve, além dos aspetos físicos, os monetários. A produção para ser economicamente eficiente requer a máxima eficiência técnica. Porém uma organização tecnicamente eficiente pode ser ineficiente em termos econômicos, se ela não usa a melhor combinação dos insumos que minimiza os custos. 
Com frequiência o vocábulo eficiência se utiliza inadequadamente como sinônimo de outros conceitos.

Um conceito que é necessário conhecer antes de analisar a eficiência é o de eficácia. A eficácia implica fazer as coisas certas, escolher os objetivos certos. É uma medida normativa do alcance dos objetivos. Assim, um administrador que seleciona um objetivo inadequadamente ou não alcance os objetivos adequados é um tomador de decisões ineficaz, mesmo que consiga a melhor relação custo beneficio. O ideal é que a organização seja eficiente e eficaz. Quando ocorre, de forma duradoura, esta situação prevalece a efetividade.

Para medir o nível de eficácia ou grau de consecução dos objetivos, utiliza-se usualmente outro conceito, o de produtividade média parcial. Ele relaciona um produto com um de seus insumos, por exemplo: a relação aluno/professor, toneladas de cereais por hectare, produção cientifica por professor. Expressa o nível de aproveitamento dos recursos empregados. Todavia os indicadores de produtividade apresentam certas limitações.

No caso de estarem associados múltiplos insumos e produtos, como ponderar essa relação? Uma possível solução dessa questão é o uso dos preços como elemento homogeneizador, ponderador. Mas, em muitas ocasiões, eles ou não estão disponíveis por ausência de mercado, no caso dos serviços públicos gratuitos, ou não são representativos, sobretudo nos mercados imperfeitos sob condições de monopólio, e isso vale para as compras e vendas públicas.

Esses indicadores também podem mostrar igual produtividade com níveis de insumos e produtos diferentes ou, o que é muito preocupante, estabelecer uma classificação onde unidades eficientes se colocam numa posição pior ou igual a outras, que não otimizam os insumos necessários de modo a gerarem o máximo de produto.

Para explicar isto, é necessário o conceito de função de produção, do qual se deriva a definição e a medida de eficiência. Esta função expressa a relação entre a quantidade física de fatores de produção ou insumos e a máxima quantidade física de bens e serviços produzidos, pressupondo o método de produção mais eficiente. A representação dessa função é:

$\mathrm{Q}=f\left(\mathrm{X}_{1}, \mathrm{X}_{2}, \mathrm{X}_{3}, \ldots . \mathrm{X}_{\mathrm{n}}\right)$, onde $\mathrm{Q}$ é a quantidade do produto e $\mathrm{X}_{1}, \mathrm{X}_{2}, \mathrm{X}_{3}, \ldots . \mathrm{X}_{\mathrm{n}}$ são as quantidades empregadas dos $\mathrm{n}$ fatores de produção.

Cabe aqui ressaltar que a função de produção, muitas vezes, é representada dependendo da quantidade empregada de trabalho, capital e matérias-primas. Também, para simplificar, é colocada em função do trabalho (L) e do capital (K), sendo representada por $\mathrm{Q}=f(\mathrm{~L}, \mathrm{~K})$. 
O Gráfico 1 mostra a forma geral da curvas da função de produção, com retornos crescentes de escalas (no segmento $0 \mathrm{~A}$ ), retornos constantes (de A a B) e retornos decrescentes (a partir de B). O conjunto de alternativas de produção é formado pela área abaixo da curva de máxima produção, que é uma espécie de fronteira das possibilidades de produção. Portanto os pontos correspondentes às unidades produtivas $\mathrm{A}, \mathrm{B}$ e $\mathrm{C}$ são níveis de produção eficientes. Isto apesar de que, ao passar do ponto A para o $\mathrm{C}$, caia a produtividade média parcial, que é medida pela inclinação da reta que une a origem do gráfico a qualquer ponto. Assim, as unidades D e C apresentam a mesma produtividade, quando $\mathrm{D}$, diferentemente de $\mathrm{C}$, é ineficiente, já que, com seu nível de insumo, o nível de produção que poderia alcançar é o da unidade B.

Conseqüentemente, quando o objetivo é a avaliação do desempenho de uma unidade em relação às outras, no sentido do nível de otimização dos recursos utilizados, o cálculo da produtividade média por insumo não é adequado.

\section{Gráfico 1: Função Produção}

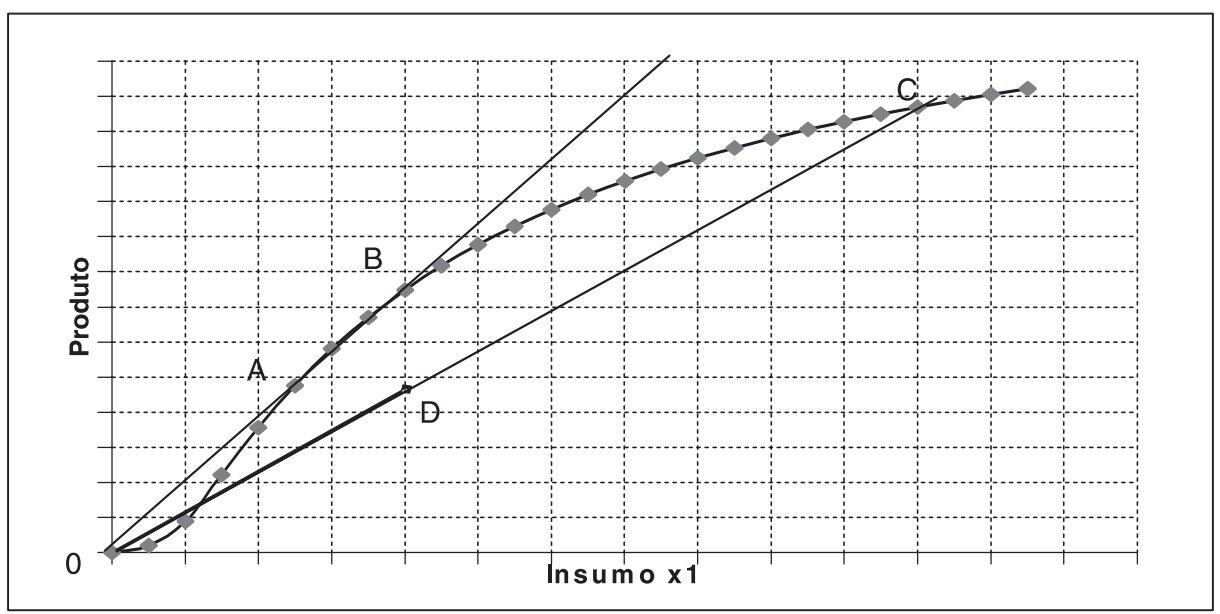

Uma segunda forma de encarar a relação entre a quantidade produzida e a quantidade utilizada dos fatores, essencial para entender o conceito e medida de eficiência, pode ser representada por uma curva chamada de isoquanta. Definese isoquanta como a curva, cujos pontos indicam todas as combinações dos fatores produtivos, que geram o mesmo nível de produção (Varian, 1997, p. 349). O Gráfico 2 ilustra as combinações dos fatores Ye X que resultam num determinado nível de produção, dados os outros fatores constantes. Isto significa que se pode atingir o mesmo nível de produção, utilizando, num extremo, uma tecnologia semiartesanal ou intensiva em mão-de-obra, com pouco capital e muito trabalho, ou, 
no outro extremo, uma altamente mecanizada, intensiva em capital com pouca mão-de-obra e muitas máquinas, ou ainda com alternativas intermediárias (Holanda, 2002, p. 361).

A isoquanta geralmente é representada por uma curva convexa, devido a que o grau de substituição dos insumos não é perfeito, isto é, à medida que se diminui o emprego de um insumo, são necessárias quantidades cada vez maiores do outro insumo para garantir o mesmo nível de produção.

Se a isoquanta representa aquelas combinações mínimas de fatores produtivos necessários para obter determinado nível de produção, ela se transforma numa fronteira que hospeda o conjunto eficiente de combinações. Por exemplo, no Gráfico 2, os pontos U1, U2 e U3 correspondem a três unidades que combinam dois fatores, $\mathrm{Y}$ e X, para produzir determinada quantidade de produto, utilizando dois processos tecnológicos. Dessas unidades, só a U1 e U2 são eficientes, pois qualquer redução dos fatores provocaria sua saída da isoquanta e a redução da produção; portanto essas unidades fornecem um padrão de eficiência técnica para as unidades que utilizam respectivamente as tecnologia 1 e 2. A unidade U3 é ineficiente, porque produz o dado nível de produto, combinando os insumos de uma forma pior a qualquer dos pontos pertencente à isoquanta. Sua ineficiência pode ser medida em relação a U1 por meio do seguinte índice: I(U3)=0U1/0U3. Conseqüentemente, os segmentos 0U1 e 0U3 podem ser expressos, utilizando-se o Teorema de Pitágoras, em função dos insumos utilizados para produzir o Q dado:

$$
I(U 3)=\sqrt{\frac{Y_{1}^{2}+X_{1}^{2}}{Y_{3}^{2}+X_{3}^{2}}}
$$

Esse valor representa o índice de eficiência de U3 e dele pode deduzir-se a redução proporcional máxima de insumos, que deveria realizar U3 para situar-se na isoquanta (Abel, 2000, p. 16).

Esta segunda forma de estudar a eficiência contempla as possíveis combinações dos fatores, considerando o nível de produção dado; portanto convencionou-se chamar de método com orientação aos inputs. Pode-se também analisar a eficiência, quando uma organização produz mais de um produto com determinada quantidade de insumos. Esse último é chamado de método com orientação aos outputs. 


\section{Gráfico 2: Isoquanta}

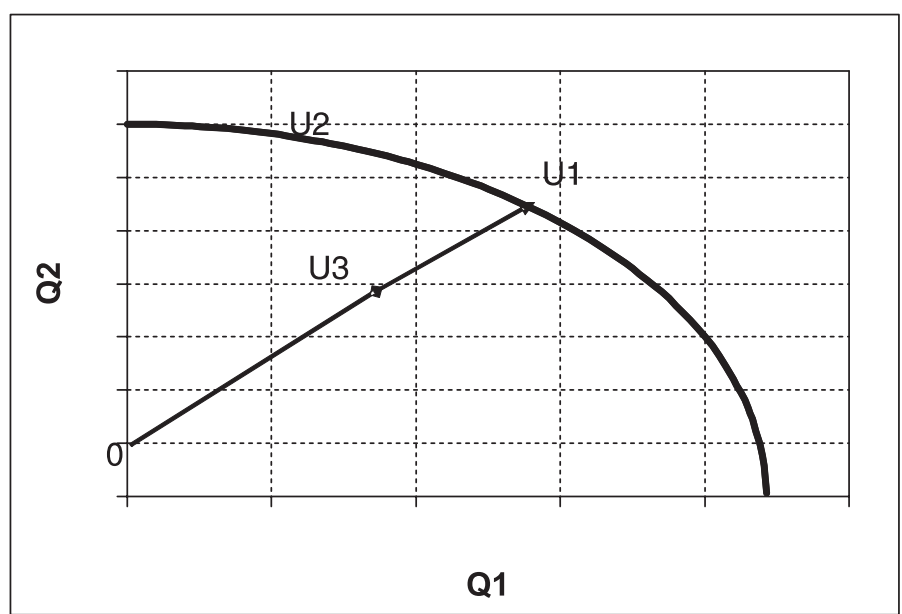

Admitindo que a organização possua determinado estoque de insumos, é importante para ela saber quais são as possibilidades que têm de produzir diversos produtos de forma eficiente. Na hipótese de produzir apenas dois produtos, podese representar no Gráfico 3 a chamada curva de possibilidades de produção ou, como outros estudiosos a denominam, curva de transformação. Define-se essa curva como a linha, em que todos os pontos revelam as diferentes combinações de dois produtos a serem produzidos com uma quantidade mínima de fatores. Sua concavidade é explicada pela Lei dos custos crescentes. Ela também se transforma numa fronteira que hospeda o conjunto eficiente de combinações de produtos. Por exemplo, no Gráfico 3, só a U1 e U2 são eficientes, já que um incremento em qualquer dos bens ou serviços produzidos exige a redução de outro produto; portanto essas unidades fornecem um padrão de eficiência técnica para as unidades que utilizam respectivamente as tecnologia 1 e 2 . A unidade U3 é ineficiente, já que tem nível de produto menor, utilizando a mesma quantidade de insumos. Sua ineficiência pode ser medida em relação a U1 por meio do seguinte índice: $\mathrm{I}(\mathrm{U} 3)=0 \mathrm{U} 1 / 0 \mathrm{U} 3$. Esse índice é maior que 1 e essa diferença indica o aumento proporcional máximo de produtos que deveria realizar U3 para ser eficiente. 
Gráfico 3: Curva de Possibilidades de Produção

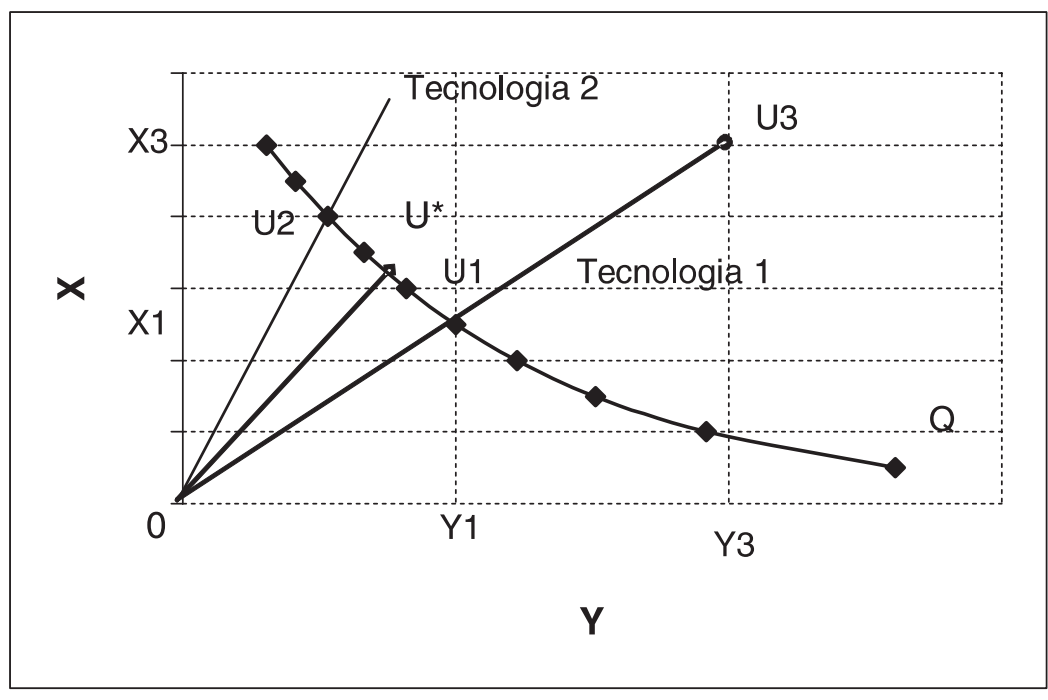

Caso a unidade produtiva ineficiente não tenha um padrão real para medir sua eficiência, seu índice é calculado comparando seu desempenho com a combinação convexa das observações insumo/produto eficientes adjacentes. Em outras palavras, supondo que os processos tecnológicos sejam divisíveis, é possível operar, combinando as tecnologias existentes, como, por exemplo, $U^{*}=1 / 2[\mathrm{U} 1]+1 / 2[\mathrm{U} 2]$ (Chiang, 1982, pp. 599-600). Como esta combinação não necessariamente existe, ela é chamada de unidade produtiva virtual ou fictícia. Essas últimas permitem também chegar a um índice de eficiência não orientado, que indicam as variações necessárias, tanto nos insumos, como nos produtos, para que as unidades ineficientes atinjam a fronteira de eficiência.

Resumindo o dito, Debreu (1951) e Farrell (1957) deduzem que uma unidade produtiva com um coeficiente de eficiência de 1 ou $100 \%$ indica que seu desempenho não pode ser melhorado por outra. Uma eficiência menor que um ou maior, dependendo do método (orientado aos inputs ou aos outputs), indicará o nível de ineficiência. Por exemplo, numa orientação aos inputs, um coeficiente de 0,90 indicará que essa unidade produtiva deverá reduzir o consumo de insumos em $10 \%$ para ser eficiente. No caso de uma orientação aos outputs, um coeficiente de 1,15 indicará que a unidade deverá aumentar todos os bens e serviços produzidos em $15 \%$ para ser eficiente.

Existe uma quarta forma de calcular a eficiência. Utilizando a chamada curva isocusto, que representa o custo total da organização, calcula-se a eficiência econômica como uma relação monetária produto/insumo. Porém 
este trabalho se limitará ao estudo da eficiência técnica, por estar orientado ao setor público e não precisar em sua análise dos preços dos insumos e produtos.

\section{Métodos de Determinação da Fronteira Eficiente}

Entre as técnicas mais utilizadas para determinar as fronteiras eficientes e os níveis de eficiência de unidades produtivas homogêneas encontram-se os métodos paramétricos e os não-paramétricos.

O método paramétrico é o mais tradicional. Utiliza a regressão múltipla e exige antecipadamente a definição da relação funcional teórica entre as variáveis envolvidas. Com dados de unidades produtivas, estima-se uma função produção com os insumos como variáveis independentes e uma ponderação de produtos ou indicadores de desempenho como variável dependente. Assim, a função de regressão é uma predição probabilística. Por exemplo, dado um nível de insumo (número de professores ou metros quadrados das instalações físicas) qual desempenho (número de diplomados e publicações) se pode esperar?

As predições resultantes representam uma média do desempenho da amostra. As diferenças entre o desempenho real de uma unidade e o desempenho médio estimado são determinadas pelos resíduos da regressão, que são negativos para as unidades que têm pior desempenho. O melhor desempenho será aquele que tenha os resíduos positivos mais altos. Conseqüentemente, por tomar como referência valores médios, a análise é uma medida imprecisa das melhores práticas.

Análises mais complexas utilizam métodos que modelam os resíduos em duas partes: uma expressa os desvios sistemáticos e outra reflete os chamados ruídos estatísticos. Com ajuda do primeiro se estima a fronteira eficiente e, assim, se determina a distância entre ela e a produção observada como ineficiência técnica.

O método não-paramétrico determina a curva de eficiência através de programação matemática de otimização, não requerendo a especificação de nenhuma relação funcional entre os insumos e produtos. Porém, sendo determinística, esta técnica é muito susceptível às observações extremas e aos erros de medidas.

Desde a perceptiva da metodologia de fronteiras de Forrell explicada acima, o desenvolvimento desse método é atribuído a Charnes, Cooper e Rhodes (1978) que passou a ser conhecido de Análise Envoltória de Dados (Data Envelopment 
Analysis -DEA) com a publicação do primeiro artigo no European Journal of Operations Research em 1978.

O método DEA tem-se aplicado com sucesso no estudo da eficiência da administração pública e organizações sem fins lucrativos. Há sido usado para comparar departamentos educacionais (escolas, faculdades, universidades e institutos de pesquisas), estabelecimentos de saúde (hospitais, clínicas), prisões, produção agrícola, instituições financeiras, países, forças armadas, esportes, transporte (manutenção de estradas, aeroportos), redes de restaurantes, franquias, cortes de justiça, instituições culturais (companhias de teatro, orquestras sinfônicas) entre outros. No entanto, na análise historiográfica do tema realizado por Silvia Kassai (2002), percebe-se a pouca utilização do Método no Brasil, sendo utilizado com frequiência nos Programas de Pós-graduação de Engenharia de Produção e Sistema da Universidade Federal de Santa Catarina e da Universidade Federal do Rio de Janeiro.

Essa nova e poderosa ferramenta permite analisar o desempenho relativo de unidades designadas por UMUs (Decision Marking Units), que utiliza os mesmos tipos de insumos para produzir os mesmos bens e/ou serviços. Os produtos e insumos podem ser variáveis contínuas, ordinais ou categóricas. Igualmente podem ser medidas em diferentes unidades (reais, números de alunos, metros quadrados, tempo médio de formação etc.).

Inicialmente, o Modelo proposto por Charnes et al. (1978), designado por CCR, foi desenhado para uma análise com retornos constantes de escala (CRS Constant Returns to Scale). Posteriormente, foi estendido por Banker, Charnes e Cooper (1984, pp. 1078-1092) para incluir retornos variáveis de escala (VRS Variable Returns to Scale) e passou a ser chamado de BCC. Assim, os Modelos básicos de DEA são conhecidos como CCR (ou CRS) e BCC (ou VRS). Cada um desses dois Modelos pode ser desenhado sob duas formas de maximizar a eficiência: 1. Reduzir o consumo de insumos, mantendo o nível de produção, ou seja, orientado ao insumo. 2. Aumentar a produção, dados os níveis de insumos, ou seja, orientado ao produto.

A formulação [1] mostra o Problema de Programação Linear (PPL) para o Modelo DEA CCR, que considera retornos constantes de escala. Esse problema, resolvido para cada uma das unidades da amostra, pode ser apresentado considerando $\mathrm{N}$ unidades, produzindo $m$ quantidade de produtos $y$, a partir de $n$ quantidades de insumo $x$. Uma unidade $o$ qualquer produz $y_{\text {ro }}$ quantidades de produtos, utilizando $x_{i o}$ insumos. A solução envolve a obtenção dos valores para $v_{i}$ e $u_{r}$ - o peso específico de cada insumo $i$ e produto $r$ - de tal forma que a medida de eficiência para a unidade produtiva analisada $h_{o}$ seja maximizada, 
sujeita à restrição de que as medidas de eficiência de todas as unidades sejam menor ou igual a um. Desse modo, a eficiência relativa da unidade analisada, definida como a soma ponderada dos produtos, dividida pela soma ponderada dos insumos, devido à restrição do problema, sempre tomará valores entre 0 e 1 .

$\operatorname{Max}_{h_{o}}=\frac{\sum_{\mathrm{r}=1}^{\mathrm{m}} \mathrm{u}_{\mathrm{r}} y_{r o}}{\sum_{i=1}^{n} v_{i} x_{i o}}$

Sujeito a

$$
\begin{array}{ll}
\frac{\sum_{\mathrm{r}=1}^{\mathrm{m}} u_{r} y_{r j}}{\sum_{\mathrm{i}=1}^{\mathrm{n}} \mathrm{v}_{\mathrm{i}} x_{i j}} \leq 1 & \mathrm{j}=1, \ldots \mathrm{o}, \ldots \mathrm{N} \\
\mathrm{u}_{\mathrm{r}}, \mathrm{v}_{\mathrm{i}} \geq 0 & \mathrm{r}=1, \ldots \mathrm{m} ; \quad \mathrm{i}=1, \ldots \mathrm{n}
\end{array}
$$

A partir daí, o método determina quais são as melhores práticas observadas, que tomam o valor de $h=1$ ou $100 \%$ e formam a fronteira eficiente com as unidades virtuais ou fictícias. A eficiência das outras unidades analisadas é medida a partir das posições relativas por elas, ocupadas em relação à fronteira. Por exemplo, se o coeficiente encontrado é 0,80 , sua interpretação indicará que essa unidade produtiva deverá reduzir equiproporcionalmente o consumo de insumos em $20 \%$ para ser eficiente. Por isso esse Modelo é chamado orientado aos insumos.

Para resolver a formulação anterior mais fácil, procede-se a uma linearização equivalente, dada a seguir:

$$
\operatorname{Max} h_{o}=\sum_{r=1}^{m} u_{r} y_{r o}
$$

Sujeito a

$\sum_{\mathrm{i}=1}^{\mathrm{n}} v_{i} x_{i o}=1$

$\sum_{\mathrm{r}=1}^{\mathrm{m}} \mathrm{u}_{\mathrm{i}} y_{r j} \leq \sum_{i=1}^{n} v_{i} x_{i j} \quad \mathrm{j}=1, \ldots \mathrm{o}, \ldots, \mathrm{N}$

$u_{r}, v_{i} \geq 0 \quad r=1, \ldots m ; \quad i=1, \ldots n$

Dependendo da situação analisada, pode ser interessante saber qual o nível de produção possível a ser alcançado, dado o nível de insumos disponível. Neste caso, utiliza-se o Modelo CCR orientado ao produto, que tem a formulação [3]: 
$\operatorname{Min} h_{o}=\sum_{r=1}^{m} v_{r} x_{r o}$

Sujeito a

$$
\begin{aligned}
& \sum_{\mathrm{i}=1}^{\mathrm{n}} u_{i} y_{i o}=1 \\
& \sum_{\mathrm{r}=1}^{\mathrm{m}} \mathrm{u}_{\mathrm{i}} y_{r j} \leq \sum_{i=1}^{n} v_{i} x_{i j} \quad \mathrm{j}=1, \ldots \mathrm{o}, \ldots, \mathrm{N} \\
& \mathrm{u}_{\mathrm{r}}, \quad \mathrm{v}_{\mathrm{i}} \geq 0 \quad \mathrm{r}=1, \ldots \mathrm{m} ; \mathrm{i}=1, \ldots \mathrm{n}
\end{aligned}
$$

O Modelo CCR com orientação aos produtos deve dar resultados equivalentes ao Modelo com orientação aos insumos. Neste caso, apenas as unidades eficientes no Modelo anterior alcançarão o coeficiente igual a um ou $100 \%$. As unidades ineficientes terão um índice que será o inverso do indicador calculado pelo Modelo com orientação aos insumos. Assim, o índice da unidade do exemplo anterior será $1,25=1 / 0,8$. Sua interpretação indicará que essa unidade produtiva deverá aumentar equiproporcionalmente os bens e serviços produzidos em $25 \%$ para ser eficiente.

O Modelo CCR com orientação tanto aos produtos como aos insumos pressupõe que as unidades avaliadas operam com retornos constantes de escalas. Estudos empíricos confirmam que a maior parte dos setores produtivos se encontra otimizando sua produção com retornos constantes de escalas (Vasconcellos \& Oliviera, 1996, p. 138). Porém, em situações de competência imperfeita, principalmente no setor público, existem organizações que podem estar operando com retornos crescentes e decrescentes de escalas. Portanto a análise anterior pode ser enriquecida com o Modelo BCC, que considera retornos variáveis de escala.

No Modelo CCR com CRS, a fronteira eficiente é dada por uma reta a partir da origem até a unidade produtiva que forma o maior raio com o eixo do insumo. O Modelo BCC com retornos variáveis de escala (VRS) forma uma fronteira convexa eficiente com as melhores unidades, independentemente da escala de operação e, assim, passa a "envelopar" as unidades ineficientes para cada escala de produção. Ao trabalhar com uma fronteira convexa, considera as unidades com baixos níveis de consumo de insumos como unidades operadas com retornos crescentes de escalas e vice-versa. Assim, o Modelo BCC admite que a eficiência máxima varie em função da economia de escala e permite comparar unidades de portes distintos (Belloni, 2000, pp. 68-69).

O Gráfico 4 mostra que o envelope do Modelo BCC (VRS) é formado pelas unidades Av, B e C. No caso do CCR (CRS) é formado pela reta originada na 
origem que passa pela unidade B. Ainda que B e C sejam eficientes com o Modelo BCC, somente a unidade B mostra-se eficiente com o Modelo CCR. A unidade A, que se mostra ineficiente também no Modelo BCC, experimenta, entretanto, uma melhora em seu índice de eficiência. Sua eficiência com retornos constantes orientada ao produto é $\mathrm{ET}_{\mathrm{CR}}=\mathrm{ZAc} / \mathrm{ZA}$ e a eficiência com retornos variáveis $-\mathrm{ET}_{\mathrm{VR}}=\mathrm{ZAv} / \mathrm{ZA}$.

\section{Gráfico 4: Curva CCR e BCC}

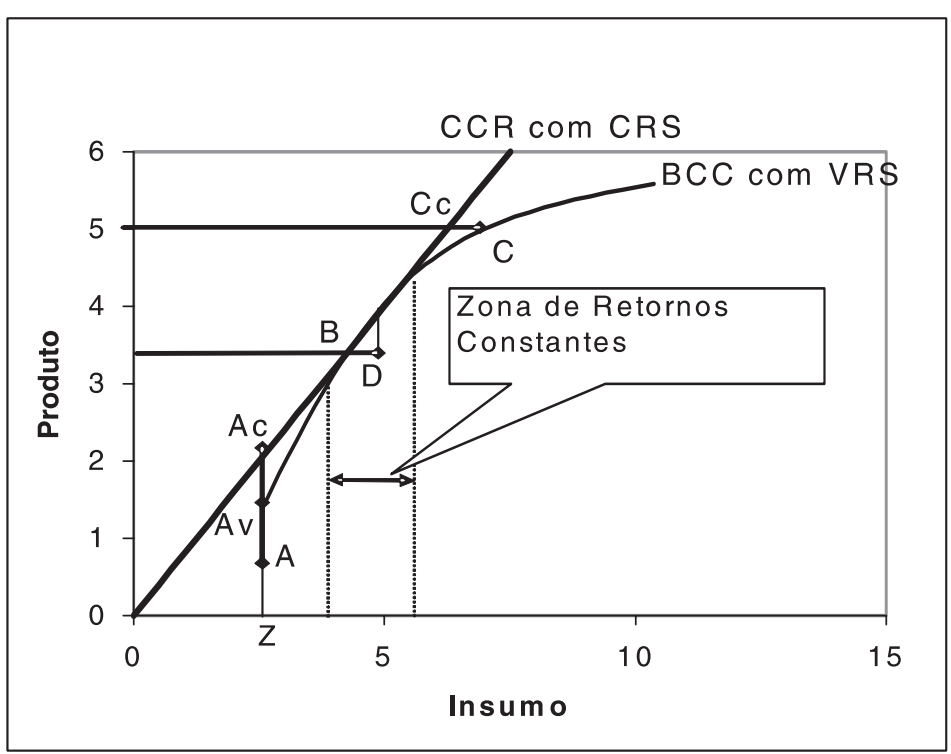

Assim, a medida de eficiência técnica calculada na ótica do produto tem diferentes conotações: a) eficiência técnica com retornos constantes de escala, denotada por $\mathrm{ET}_{\mathrm{CR}}$ e chamada de eficiência técnica global ou produtiva; b) a eficiência técnica com retornos variáveis conceituada como eficiência técnica pura e denotada $\mathrm{ET}_{\mathrm{VR}}$; e c) a relação entre as duas anteriores, definida como eficiência de escala, $\mathrm{ET}_{\mathrm{SC}}=\mathrm{ET}_{\mathrm{CR}} / \mathrm{ET}_{\mathrm{VR}}=\mathrm{ZAc}_{\mathrm{ZA}}$. Daí pode-se, conforme Gráfico 4, deduzir:

- $\mathrm{ET}_{\mathrm{CR}}=1$ - eficiência produtiva com eficiência pura e de escala (caso B);

- $\mathrm{ET}_{\mathrm{CR}}>1$ - ineficiência produtiva decorrente de ineficiência pura (casos D), de escala (caso C) ou de ambos (Caso A);

. $\mathrm{ET}_{\mathrm{SC}}=1$ - porte ótimo com ineficiência pura (caso D) ou não (caso B);

. $\mathrm{ET}_{\mathrm{SC}}>1$ - porte inapropriado com eficiência pura (caso C) ou não (caso A); 
$\mathrm{ET}_{\mathrm{VR}}=1$ - eficiência pura com escala apropriada (caso B) ou não (caso C);

. $\mathrm{ET}_{\mathrm{VR}}>1$ - ineficiência pura com escala apropriada (caso D) ou não (caso A).

No Modelo BCC com retornos variáveis de escala (VRS), os índices de eficiência, como se viu, dependem da orientação escolhida. Caso se pretenda maximizar a produção dados os níveis de insumos (orientação ao produto), a formulação do Modelo BCC é:

$\operatorname{Min} h_{o}=\sum_{r=1}^{m} v_{r} x_{r o}+\mathrm{v}_{\mathrm{o}}$

Sujeito a

$\sum_{\mathrm{i}=1}^{\mathrm{n}} u_{i} y_{i o}=1$

$\sum_{\mathrm{r}=1}^{\mathrm{m}} \mathrm{u}_{\mathrm{i}} y_{r j}-\sum_{i=1}^{n} v_{i} x_{i j}-v_{o} \leq 0 \quad \mathrm{j}=1, \ldots \mathrm{o}, \ldots, \mathrm{N}$

$u_{r}, v_{i} \geq 0 \quad r=1, \ldots m ; \quad i=1, \ldots n$

Quando se deseja minimizar os insumos, sem alteração do nível de produção, a formulação do Modelo é:

$\operatorname{Max} h_{o}=\sum_{r=1}^{m} u_{r} y_{r o}-u_{\mathrm{o}}$

Sujeito a

$\sum_{\mathrm{i}=1}^{\mathrm{n}} v_{i} x_{i o}=1$

$\sum_{\mathrm{r}=1}^{\mathrm{m}} \mathrm{u}_{\mathrm{i}} y_{r j}-\sum_{i=1}^{n} v_{i} x_{i j}-u_{o} \leq 0 \quad \mathrm{j}=1, \ldots \mathrm{o}, \ldots, \mathrm{N}$

$u_{r}, v_{i} \geq 0 \quad r=1, \ldots m ; i=1, \ldots n$

Percebe-se, que [4] e [5] se distinguem das formulações do Modelo CCR pela existência das variáveis $\mathrm{v}_{\mathrm{o}}$ e $\mathrm{u}_{\mathrm{o}}$ que representam os retornos variáveis de escala. Quando negativas, indicam retornos crescentes; quando positivas, retornos decrescentes; e, caso sejam nulas, retornos constantes de escalas. Além disso, os índices de eficiências do Modelo BCC com orientação ao produto e ao insumo não são iguais, como acontece com o Modelo CCR, devido à convexidade da fronteira eficiente, mas mantêm à classificação entre as unidades eficientes e ineficientes.

A aplicação da DEA exige uma sequiência de passos. Inicialmente se selecionam as unidades produtivas (DMUs). Posteriormente, descreve-se o 
processo produtivo das unidades analisadas para identificar e classificar os insumos e produtos. Realizado isso, passa-se a executar o método, utilizando os softwares disponíveis.

As unidades selecionadas devem ser homogêneas, isto é, produzir os mesmos bens e serviços, utilizando insumos iguais. Quanto ao número de unidades, não existem normas definidas. Porém, quanto maior a quantidade de unidades analisadas, maior será a capacidade discriminatória do Modelo. Alguns autores sugerem que o número de unidades analisadas seja 5 vezes o número de insumos e produtos especificados (Gonzáles-Araya, 2003).

Por esta última razão, em parte, deve-se evitar a inclusão de grande número de insumos e produtos. A consolidação dos insumos e produtos em categorias básicas evita também a redundância. Devem ser, portanto, selecionados os insumos e os produtos que melhor contribuem com a análise da eficiência e que tenham informações não incluídas em outras variáveis. Subestimar e/ou superestimar os insumos e produtos acarretará resultados tendenciosos. A ineficiência pode ser resultado das variáveis relevantes ausentes.

Muitas vezes uma variável representa um produto, cujas quantidades devem ser minimizadas (ex. evasão escolar, acidente de trabalho, reprovação, poluição, reclamações, devoluções). Nesses casos, recomenda-se tratar essa variável como insumo. Pode-se, alternativamente, transformar essa variável, criando nova escala inversa à original, sem a necessidade de transformá-la em insumo. É importante também que os inputs contemplem atributos do ambiente em que operam as unidades analisadas.

Para executar o Modelo, utilizam-se softwares como Frontier Analyst, Excel Solver, DEAxl Tool do Excel®. Neste trabalho, usar-se-á um exemplo calculado com o macro DEAxl disponível na internet gratuitamente.

\section{Um Exemplo de Aplicação do Método DeA}

Pode supor-se uma universidade pública com vinte unidades acadêmicas localizadas em cidades de mesmo porte e distribuídas racionalmente pelo interior de um Estado, para as quais se relaciona, como exemplo didático, o número de professores, o valor dos ativos em $\mathrm{R} \$ 1000,00$, o número de alunos formados e a produção científica para o ano 2000, conforme as cinco primeiras colunas da Tabela 1. Para ver uma metodologia mais depurada de escolha dos insumos e produtos de IESs, referencia-se Lopes (1998). 
Tabela 1: Dados das Unidades Acadêmicas e Resultados do Modelo DEA -CCR

\begin{tabular}{|c|c|c|c|c|c|c|c|}
\hline \multirow[b]{2}{*}{ Unidade } & \multicolumn{2}{|c|}{ Insumos } & \multicolumn{2}{|c|}{ Produtos } & \multirow{2}{*}{\begin{tabular}{|c|} 
Eficiência 2- \\
1 \\
Orientada \\
aos inputs
\end{tabular}} & \multirow{2}{*}{$\begin{array}{c}\text { Eficiência 2- } \\
2 \text { Orientada } \\
\text { aos inputs }\end{array}$} & \multirow{2}{*}{$\begin{array}{l}\text { Eficiência 2- } \\
2 \text { Orientada } \\
\text { aos outputs }\end{array}$} \\
\hline & $\begin{array}{c}\mathrm{N}^{\circ} \\
\text { Professores }\end{array}$ & $\begin{array}{c}\text { Ativos em } \$ \\
1000\end{array}$ & $\begin{array}{l}\mathrm{N}^{\circ} \text { Alunos } \\
\text { Formados }\end{array}$ & $\begin{array}{l}\text { Produção. } \\
\text { Cientifica }\end{array}$ & & & \\
\hline $\mathrm{I}$ & 44 & 1487,85 & 80 & 62 & $52,48 \%$ & $100,00 \%$ & $100,00 \%$ \\
\hline II & 33 & 1599,78 & 78 & 4 & $59,09 \%$ & $59,09 \%$ & $169,23 \%$ \\
\hline III & 41 & 3888,61 & 158 & 86 & $96,34 \%$ & $100,00 \%$ & $100,00 \%$ \\
\hline IV & 59 & 5147,81 & 197 & 8 & $83,47 \%$ & $83,47 \%$ & $119,80 \%$ \\
\hline $\mathrm{V}$ & 66 & 5221,85 & 264 & 92 & $100,00 \%$ & $100,00 \%$ & $100,00 \%$ \\
\hline VI & 65 & 5299,05 & 132 & 68 & $50,77 \%$ & $55,42 \%$ & $180,45 \%$ \\
\hline VII & 74 & 7475,83 & 234 & 104 & $79,05 \%$ & $80,51 \%$ & $124,21 \%$ \\
\hline VIII & 132 & 10443,69 & 528 & 185 & $100,00 \%$ & $100,00 \%$ & $100,00 \%$ \\
\hline IX & 33 & 2610,92 & 93 & 46 & $70,45 \%$ & $76,07 \%$ & $131,47 \%$ \\
\hline $\mathrm{X}$ & 74 & 7475,83 & 234 & 16 & $79,05 \%$ & $79,05 \%$ & $126,50 \%$ \\
\hline $\mathrm{XI}$ & 72 & 7475,83 & 288 & 101 & $100,00 \%$ & $100,00 \%$ & $100,00 \%$ \\
\hline XII & 78 & 7475,83 & 312 & 9 & $100,00 \%$ & $100,00 \%$ & $100,00 \%$ \\
\hline XIII & 43 & 5606,87 & 172 & 43 & $100,00 \%$ & $100,00 \%$ & $100,00 \%$ \\
\hline XIV & 71 & 7475,83 & 284 & 71 & $100,00 \%$ & $100,00 \%$ & $100,00 \%$ \\
\hline $\mathrm{XV}$ & 85 & 7479,83 & 340 & 85 & $100,00 \%$ & $100,00 \%$ & $100,00 \%$ \\
\hline XVI & 28 & 1500,78 & 80 & 28 & $71,43 \%$ & $75,39 \%$ & $132,64 \%$ \\
\hline XVII & 32 & 1599,78 & 90 & 32 & $70,31 \%$ & $77,32 \%$ & $129,33 \%$ \\
\hline XVIII & 41 & 1600,78 & 164 & 41 & $100,00 \%$ & $100,00 \%$ & $100,00 \%$ \\
\hline XIX & 30 & 1599,88 & 60 & 30 & $50,00 \%$ & $66,50 \%$ & $150,37 \%$ \\
\hline $\mathrm{XX}$ & 32 & 1599,78 & 67 & 32 & $52,34 \%$ & $69,50 \%$ & $143,89 \%$ \\
\hline
\end{tabular}

As outras duas colunas mostram os coeficientes de eficiência calculados, utilizando o Método orientado ao insumo, considerando retornos constantes de escala (Equações [2]). A sexta coluna calculou-se considerando os dois insumos e o primeiro produto. A sétima, com a qual se trabalhará, contemplou os dois insumos e os dois produtos. É evidente que algumas unidades melhoraram sua eficiência, quando se incluiu a produção científica, evidenciando o impacto desse produto no resultado final.

De início para calcular a eficiência, utilizando a opção DEAxl, o usuário deve preparar uma planilha com as informações do problema em estudo, conforme ilustrado na Figura 1. A Figura 2 mostra a primeira tela que se abre ao acionar a ferramenta DEAxl. O nome do projeto é preenchido automaticamente. A matriz de variáveis é carregada com os dados das colunas dos insumos e produtos, incluindo os rótulos. A matriz de DMUs é preenchida com os dados das linhas, que incluem as unidades analisadas e seus respectivos insumos e produtos. 


\section{Figura 1: Planilha com os Dados Iniciais}

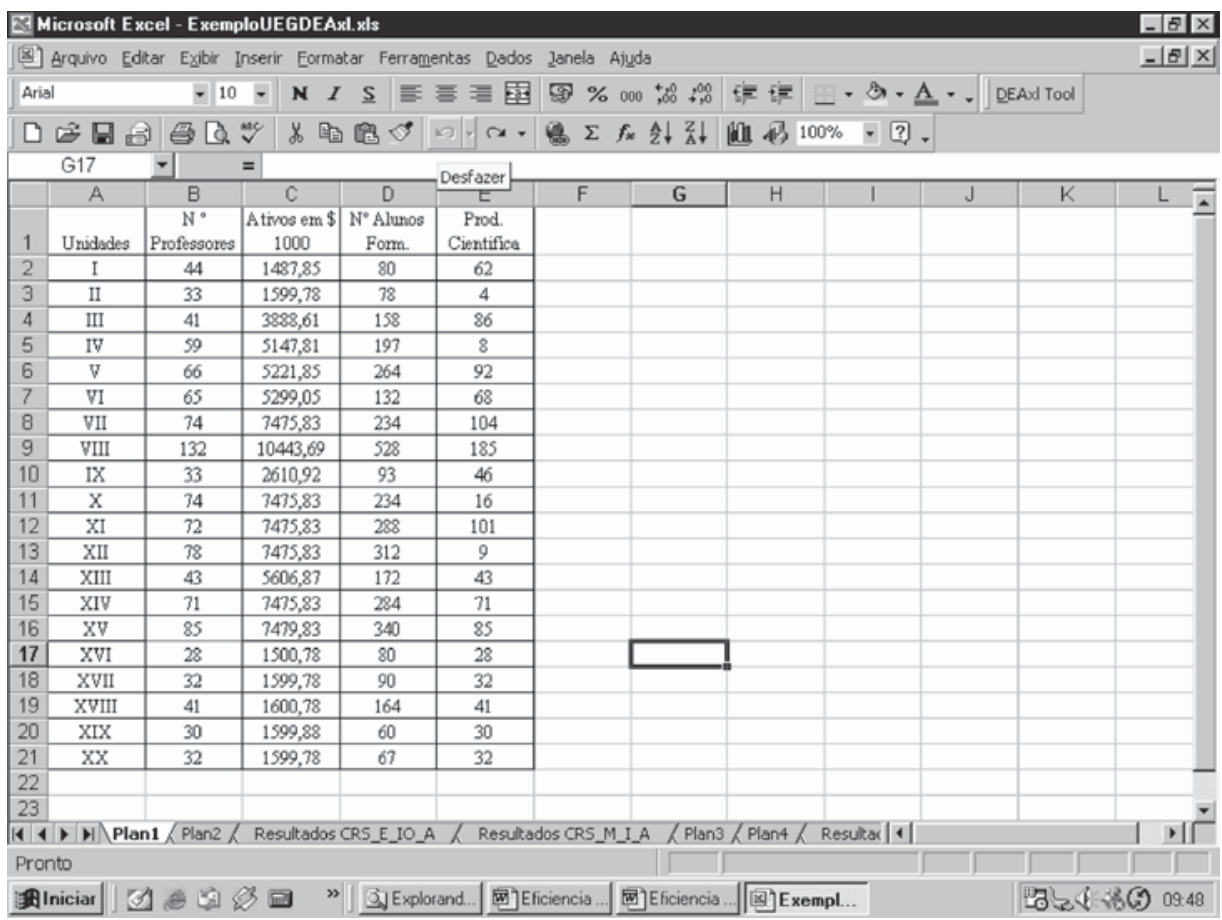

Figura 2: Primeira Tela do DEAxl

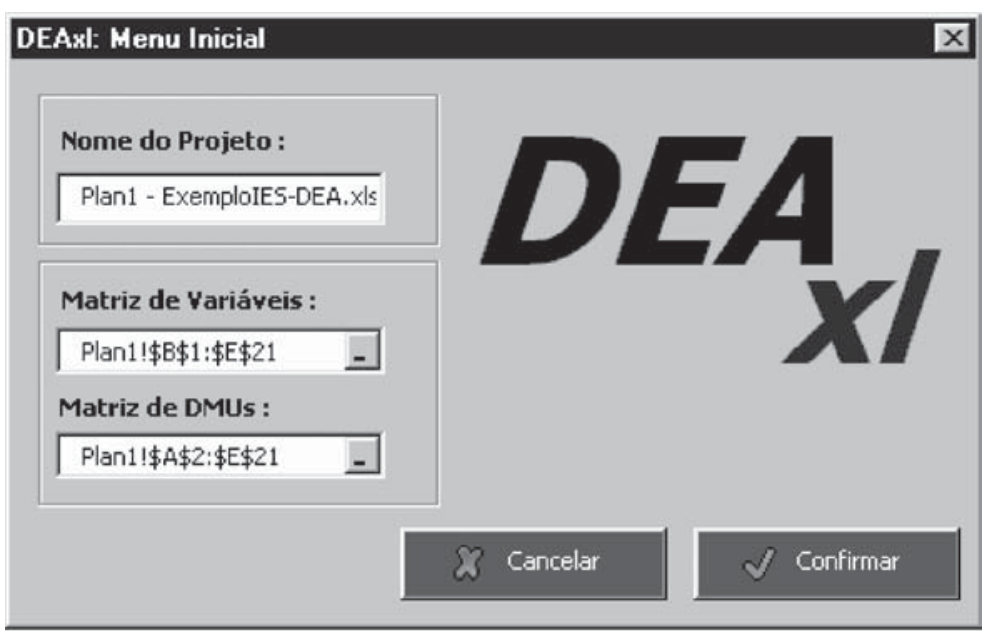

Após confirmar, aparecerá uma segunda tela apresentada na Figura 3. As variáveis irão aparecer na caixa central, chamada matriz de variáveis. Nesse 
momento, poderão ser selecionadas como input ou output, de acordo com o estudo. Para isso, o usuário deve selecionar as variáveis inputs e clicar a seta esquerda. $\mathrm{O}$ mesmo deve ser feito com as varáveis outputs, utilizando a seta direita. Seguidamente, deve-se ainda determinar o Modelo DEA que será executado. Para isso, apresentam-se várias opções das quais nos interessam: CRS ou VRS - Retorno de escala constante ou variável; Orientação ao input ou Orientação ao output.

\section{Figura 3: Segunda Tela do DEAx1}

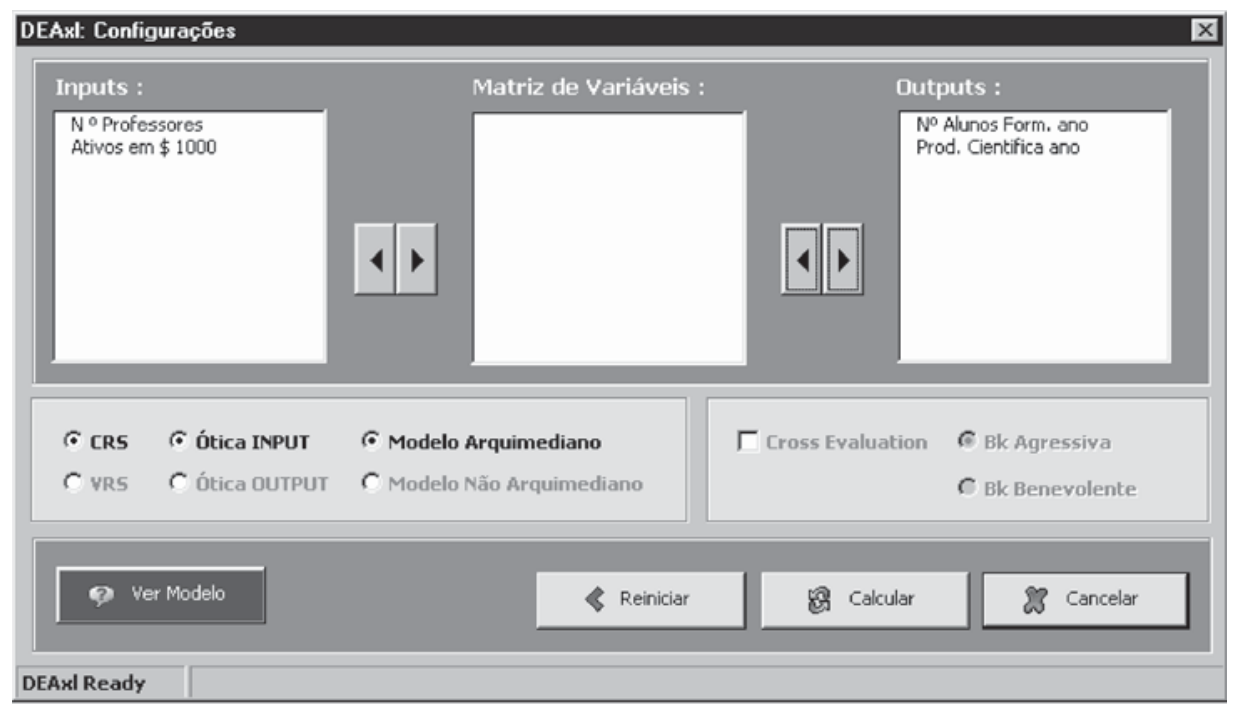

Inicialmente, serão selecionados o Modelo de retorno de escala constante (CRS) e a orientação ao input. Seguidamente, pressiona-se a tecla calcular. Terminado o cálculo, pode-se fechar a tela e se terá duas novas planilha de Excel, nomeadas Resultados CRS_E_IO_A e Resultados CRS_M_I_A. Essa última dá os coeficientes de eficiência, registrados na coluna 7 da Tabela 1, e os pesos relativos dos insumos e produtos para as respectivas unidades.

Anteriormente explicou-se que se o coeficiente de eficiência era menor que $100 \%$, isto significava que a unidade era ineficiente, sendo tanto mais ineficiente quanto menor é esse valor. Para chegar a ser eficiente, a unidade teria que reduzir todos seus insumos no valor faltante para $100 \%$ simultaneamente, isto é, sem mudar a forma de combinação (mix) dos insumos. Por exemplo, a unidade acadêmica II, com seu coeficiente $59,1 \%$, teria que cortar todos os seus insumos em $40,9 \%$, sem alterar o output-mix.

A coluna sete ilustra que somente são globalmente eficientes as unidades I, III, 
IV, VIII, XI, XII, XIII, XIV, XV, XVIII - 50\% das unidades; as outras unidades são ineficientes, ou seja, apresentam insumos superdimensionadas.

Esses resultados permitem identificar e reconhecer as melhores práticas. Cumpre analisar a causa da eficiência, para identificar possíveis irracionalidades nas unidades ineficientes. Por exemplo, percebe-se, na unidade II, a existência de recursos ociosos ou inutilizados num valor de $40,9 \%$, uma vez que, com esses insumos, uma unidade eficiente pode produzir uma combinação maior de produtos. Essa informação pode ser utilizada para apoiar uma redução dos custos. Também, esses dados dão subsídios para a implantação de um sistema de controle e avaliação institucional.

Por outro lado, como se mostrou, pode-se calcular os níveis de eficiência, utilizando o Modelo CCR, orientado ao produto expresso na formulação [3]. A coluna 8 da Tabela 1 fornece os valores do cálculo. Esses resultados são idênticos aos do Modelo com orientação aos insumos. Apenas as unidades eficientes no Modelo anterior têm na coluna 8 um coeficiente igual a 1 ou 100\%. As unidades ineficientes alcançam um coeficiente que é o inverso do indicador calculado pelo Modelo com orientação aos insumos; assim, o coeficiente da unidade II é 1,6923=1/ 0,5909. Sua interpretação indicará o incremento máximo simultâneo $(69,23 \%)$, que essa unidade acadêmica deverá realizar em todos os produtos para ser eficiente. Essa informação poderá ser utilizada, caso exista uma política de expansão que presuma a maximização da produção a partir dos insumos disponíveis.

Os dois Modelos supracitados indicam respectivamente a redução de todos os insumos sem alterar o output-mix e o incremento dos produtos sem modificar o input-mix. Porém, alternativamente, podem-se calcular as mudanças que cada unidade tem que fazer tanto nos insumos como nos produtos, para se tornar eficiente.

A outra planilha (Resultados CRS_E_IO_A) nos dá esse subsídio. Fornece, conforme Tabela 2, os índices de eficiência e os chamados preços sombra, esses últimos encontrados na intercessão das linhas das unidades ineficientes com as colunas das unidades padrões para as ineficientes. O preço sombra permite calcular as possíveis metas a serem estabelecidas para tornar as unidades eficientes. Por exemplo, pela análise da linha da unidade II, conclui-se que sua ineficiência é calculada, tomando-se como referência uma unidade virtual formada pelas unidades VIII e XVIII, já que na intercessão se encontram preços sombra ( $\mu \mathrm{i}$ ) maiores que zero $(0,03478$ e 0,363639$)$. Esses valores aplicados aos insumos e produtos das unidades VIII e XVIII determinam as variações necessárias em cada insumo e produto para que a unidade II passe a ser eficiente. 
Tabela 2: Dados da Planilha Resultados CRS_E_IO_A

\begin{tabular}{|c|c|c|c|c|c|c|c|c|c|c|c|c|c|c|c|c|c|c|c|c|c|}
\hline $\begin{array}{c}\mathrm{DM} \\
\mathrm{U}\end{array}$ & $\begin{array}{c}\text { Eficiênci } \\
a\end{array}$ & $\mu 1$ & $\mu 2$ & $\mu 3$ & $\mu 4$ & $\mu 5$ & $\mu 6$ & $\mu 7$ & $\mu 8$ & $\mu 9$ & $\mu 10$ & $\mu 11$ & $\mu 12$ & $\mu 13$ & $\mu 14$ & $\mu 15$ & $\mu 16$ & $\mu 17$ & $\mu 18$ & $\mu 19$ & $\mu 20$ \\
\hline I & $100 \%$ & 1,00 & 0,00 & 0,00 & 0,00 & 0,00 & 0,00 & 0,00 & 0,00 & 0,00 & 0,00 & 0,00 & 0,00 & 0,00 & 0,00 & 0,00 & 0,00 & 0,00 & 0,00 & 0,00 & 0,00 \\
\hline II & $59 \%$ & 0,00 & 0,00 & 0,00 & 0,00 & 0,00 & 0,00 & 0,00 & 0,03 & 0,00 & 0,00 & 0,00 & 0,00 & 0,00 & 0,00 & 0,00 & 0,00 & 0,00 & 0,36 & 0,00 & 0,00 \\
\hline III & $100 \%$ & 0,00 & 0,00 & 1,00 & 0,00 & 0,00 & 0,00 & 0,00 & 0,00 & 0,00 & 0,00 & 0,00 & 0,00 & 0,00 & 0,00 & 0,00 & 0,00 & 0,00 & 0,00 & 0,00 & 0,00 \\
\hline IV & $83 \%$ & 0,00 & 0,00 & 0,00 & 0,00 & 0,00 & 0,00 & 0,00 & 0,00 & 0,00 & 0,00 & 0,00 & 0,54 & 0,00 & 0,00 & 0,00 & 0,00 & 0,00 & 0,18 & 0,00 & 0,00 \\
\hline V & $100 \%$ & 0,00 & 0,00 & 0,00 & 0,00 & 0,00 & 0,00 & 0,00 & 0,50 & 0,00 & 0,00 & 0,00 & 0,00 & 0,00 & 0,00 & 0,00 & 0,00 & 0,00 & 0,00 & 0,00 & 0,00 \\
\hline VI & $55 \%$ & 0,08 & 0,00 & 0,68 & 0,00 & 0,00 & 0,00 & 0,00 & 0,00 & 0,00 & 0,00 & 0,00 & 0,00 & 0,00 & 0,00 & 0,00 & 0,00 & 0,00 & 0,11 & 0,00 & 0,00 \\
\hline VII & $81 \%$ & 0,00 & 0,00 & 0,72 & 0,00 & 0,00 & 0,00 & 0,00 & 0,00 & 0,00 & 0,00 & 0,42 & 0,00 & 0,00 & 0,00 & 0,00 & 0,00 & 0,00 & 0,00 & 0,00 & 0,00 \\
\hline VIII & $100 \%$ & 0,00 & 0,00 & 0,00 & 0,00 & 0,00 & 0,00 & 0,00 & 1,00 & 0,00 & 0,00 & 0,00 & 0,00 & 0,00 & 0,00 & 0,00 & 0,00 & 0,00 & 0,00 & 0,00 & 0,00 \\
\hline IX & $76 \%$ & 0,05 & 0,00 & 0,44 & 0,00 & 0,00 & 0,00 & 0,00 & 0,00 & 0,00 & 0,00 & 0,00 & 0,00 & 0,00 & 0,00 & 0,00 & 0,00 & 0,00 & 0,11 & 0,00 & 0,00 \\
\hline$x$ & $79 \%$ & 0,00 & 0,00 & 0,00 & 0,00 & 0,00 & 0,00 & 0,00 & 0,01 & 0,00 & 0,00 & 0,00 & 0,62 & 0,21 & 0,00 & 0,00 & 0,00 & 0,00 & 0,00 & 0,00 & 0,00 \\
\hline$X I$ & $100 \%$ & 0,00 & 0,00 & 0,00 & 0,00 & 0,00 & 0,00 & 0,00 & 0,00 & 0,00 & 0,00 & 1,00 & 0,00 & 0,00 & 0,00 & 0,00 & 0,00 & 0,00 & 0,00 & 0,00 & 0,00 \\
\hline XII & $100 \%$ & 0,00 & 0,00 & 0,00 & 0,00 & 0,00 & 0,00 & 0,00 & 0,00 & 0,00 & 0,00 & 0,00 & 1,00 & 0,00 & 0,00 & 0,00 & 0,00 & 0,00 & 0,00 & 0,00 & 0,00 \\
\hline XIII & $100 \%$ & 0,00 & 0,00 & 0,00 & 0,00 & 0,00 & 0,00 & 0,00 & 0,00 & 0,00 & 0,00 & 0,00 & 0,00 & 1,00 & 0,00 & 0,00 & 0,00 & 0,00 & 0,00 & 0,00 & 0,00 \\
\hline XIV & $100 \%$ & 0,00 & 0,00 & 0,00 & 0,00 & 0,00 & 0,00 & 0,00 & 0,20 & 0,00 & 0,00 & 0,00 & 0,15 & 0,75 & 0,00 & 0,00 & 0,00 & 0,00 & 0,00 & 0,00 & 0,00 \\
\hline$X V$ & $100 \%$ & 0,00 & 0,00 & 0,00 & 0,00 & 0,00 & 0,00 & 0,00 & 0,41 & 0,00 & 0,00 & 0,00 & 0,31 & 0,16 & 0,00 & 0,00 & 0,00 & 0,00 & 0,00 & 0,00 & 0,00 \\
\hline$X \mathrm{XV}$ & $75 \%$ & 0,04 & 0,00 & 0,14 & 0,00 & 0,00 & 0,00 & 0,00 & 0,00 & 0,00 & 0,00 & 0,00 & 0,00 & 0,00 & 0,00 & 0,00 & 0,00 & 0,00 & 0,34 & 0,00 & 0,00 \\
\hline XVII & $77 \%$ & 0,09 & 0,00 & 0,13 & 0,00 & 0,00 & 0,00 & 0,00 & 0,00 & 0,00 & 0,00 & 0,00 & 0,00 & 0,00 & 0,00 & 0,00 & 0,00 & 0,00 & 0,38 & 0,00 & 0,00 \\
\hline XVIII & $100 \%$ & 0,00 & 0,00 & 0,00 & 0,00 & 0,00 & 0,00 & 0,00 & 0,00 & 0,00 & 0,00 & 0,00 & 0,00 & 0,00 & 0,00 & 0,00 & 0,00 & 0,00 & 1,00 & 0,00 & 0,00 \\
\hline XIX & $67 \%$ & 0,20 & 0,00 & 0,14 & 0,00 & 0,00 & 0,00 & 0,00 & 0,00 & 0,00 & 0,00 & 0,00 & 0,00 & 0,00 & 0,00 & 0,00 & 0,00 & 0,00 & 0,13 & 0,00 & 0,00 \\
\hline$x x$ & $69 \%$ & 0,22 & 0,00 & 0,13 & 0,00 & 0,00 & 0,00 & 0,00 & 0,00 & 0,00 & 0,00 & 0,00 & 0,00 & 0,00 & 0,00 & 0,00 & 0,00 & 0,00 & 0,18 & 0,00 & 0,00 \\
\hline
\end{tabular}

A Tabela 3 fornece os cálculos. Na primeira coluna das unidades referências (VIII e XVIII) encontram-se o preço sombra e os valores atuais de seus insumos e produtos; na segunda, a multiplicação do preço sombra pelo valor de cada variável. Do somatório dessas metas resulta a meta total, o valor, que deve ser alcançado. A comparação desse último com o valor atual da unidade II define a diferença em termos absolutos e a variação percentual. Os cálculos mostram que existe espaço para melhorias. As sugestões dadas referem-se a um aumento da produção científica em $433,5 \%$, a uma redução de $50,81 \%$ no número de professores e, de 40,93\% nos investimentos em ativos. A Tabela 3 , também, mostra a extensão na qual cada unidade referência contribuiu na determinação das metas para a eficiência. Identifica-se que a unidade XVIII é a chave para comparar o desempenho da unidade II. 
Tabela 3: Metas para a Unidade Acadêmica II

\begin{tabular}{|c|c|c|c|c|c|c|c|c|}
\hline Referencia & \multicolumn{2}{|c|}{ Unidade VIII } & \multicolumn{2}{|c|}{ Unidade XVIII } & \multicolumn{4}{c|}{ Unidade II } \\
\hline & & Meta & & Meta & Meta total & Atual & Diferença & Variação\% \\
\hline Preço Sombra & 0,03478 & & 0,36364 & & & & & \\
\hline Professores & 132 & 4,59 & 41 & 14,91 & 19,5 & 33 & $-16,77$ & $-50,81$ \\
\hline Ativos & 10443,69 & 363,22 & 1600,78 & 582,11 & 945,33 & 1599,78 & $-654,82$ & $-40,93$ \\
\hline Alunos & 528 & 18,36 & 164 & 59,64 & 78 & 78 & 0 & 0 \\
\hline $\begin{array}{c}\text { Produção } \\
\text { Cientifica. }\end{array}$ & 185 & 6,43 & 41 & 14,91 & 21,34 & 4 & 17,34 & 433,5 \\
\hline
\end{tabular}

Conclusões similares podem ser obtidas para as outras unidades acadêmicas ineficientes.

A análise da hipotética universidade pública, com unidades de diferentes portes, deve ser continuada com a aplicação do Modelo BCC, que considera os retornos variáveis de escala e permite discriminar a ineficiência de escala $\left(\mathrm{ET}_{\mathrm{SC}}\right)$ da técnica pura $\left(\mathrm{ET}_{\mathrm{VR}}\right)$, conforme visto.

Para a execução do Modelo BCC com orientação aos insumos, conforme Figura 3, seleciona-se o Modelo de retornos de escala variáveis (VRS) e a orientação ao input. Seguindo os procedimentos já vistos, ter-se-ão duas novas planilhas de Excel, nomeadas Resultados VRS_M_I_A e Resultados VRS_E_I_A.

Para calcular o Modelo BCC com orientação ao produto, utilizou-se a opção Solver do Excel, já que o programa DEAxl dá erro no calculo do Modelo BCC orientado ao produto. Os valores obtidos são apresentados na coluna 3 da Tabela 4. Eles mostram que somente são eficientes as unidades I, III, V, VIII, XI, XII, XIII, XIV, XV, XVI, XVIII, uma unidade a mais que no Modelo CCR CRS. Cabe ressaltar também que nenhuma dessas unidades recebeu pontuação mais baixa que no cálculo, usando retornos constantes e registrados na coluna 2 da Tabela 4. Isto se deve a que o índice calculado corresponde à eficiência técnica pura, que depura os efeitos da ineficiência decorrente do inadequado porte da unidade.

A discriminação entre eficiência técnica pura e de escala, mostrada na Tabela 4, foi calculada na óptica dos produtos, utilizando-se a fórmula vista anteriormente $\left(\mathrm{ET}_{\mathrm{SC}}=\mathrm{ET}_{\mathrm{CR}} / \mathrm{ET}_{\mathrm{VR}}\right)$.

Pela análise da Tabela 4, percebe-se que as unidades II, VI, VII, IX, XVI, XVII, XIX e XX apresentam portes inapropriados, uma vez que têm eficiências de escala superiores a $100 \%$, sendo que delas só a unidade XVI tem eficiência pura. As unidades IV e X, no entanto, apresentam tamanhos ótimos com ineficiência pura. 
Tabela 4: Eficiência Produtiva, Pura e de Escala Calculado com Orientação ao Produto

\begin{tabular}{|c|c|c|c|c|}
\hline Unidade acadêmica & $\begin{array}{c}\text { Eficiência Produtiva } \\
\mathrm{ET}_{\mathrm{CR}}\end{array}$ & $\begin{array}{c}\text { Eficiência Pura - } \\
\mathrm{ET}_{\mathrm{VR}}\end{array}$ & $\begin{array}{c}\text { Eficiência de Escala - } \\
\mathrm{ET}_{\mathrm{SC}}\end{array}$ & Tipo de ineficiência \\
\hline I & $100,00 \%$ & $100,00 \%$ & $100,00 \%$ & \\
\hline II & $169,23 \%$ & $143,98 \%$ & $117,53 \%$ & Pura e de Escala \\
\hline III & $100,00 \%$ & $100,00 \%$ & $100,00 \%$ & Pura \\
\hline IV & $119,80 \%$ & $119,80 \%$ & $100,00 \%$ & $100,00 \%$ \\
\hline V & $100,00 \%$ & $100,00 \%$ & $112,79 \%$ & Pura e de Escala \\
\hline VI & $180,45 \%$ & $159,99 \%$ & $105,97 \%$ & Pura e de Escala \\
\hline VII & $124,21 \%$ & $117,21 \%$ & $100,00 \%$ & \\
\hline VIII & $100,00 \%$ & $100,00 \%$ & $120,21 \%$ & Pura e de Escala \\
\hline IX & $131,47 \%$ & $109,36 \%$ & $100,00 \%$ & Pura \\
\hline X & $126,50 \%$ & $126,50 \%$ & $100,00 \%$ & \\
\hline XI & $100,00 \%$ & $100,00 \%$ & $100,00 \%$ & \\
\hline XII & $100,00 \%$ & $100,00 \%$ & $100,00 \%$ & \\
\hline XIII & $100,00 \%$ & $100,00 \%$ & $100,00 \%$ & \\
\hline XIV & $100,00 \%$ & $100,00 \%$ & $100,00 \%$ & \\
\hline XV & $100,00 \%$ & $100,00 \%$ & $132,64 \%$ & Pura e de Escala \\
\hline XVI & $132,64 \%$ & $100,00 \%$ & $118,71 \%$ & Pura e de Escala \\
\hline XVII & $129,33 \%$ & $108,94 \%$ & $100,00 \%$ & \\
\hline XVIII & $100,00 \%$ & $100,00 \%$ & $134,56 \%$ & Pura e de Escala \\
\hline XIX & $150,37 \%$ & $111,75 \%$ & $121,83 \%$ & Pura e de Escala \\
\hline XX & $143,89 \%$ & $118,11 \%$ & &
\end{tabular}

A utilização do software Solver do Excel permite também realizar análises mais complexas, calcular as variáveis $\mathrm{v}_{\mathrm{o}}$ e $\mathrm{u}_{\mathrm{o}}$ da fórmula [4] e [5] que representam os retornos variáveis de escala. Quando negativas, indicam retornos crescentes; quando positivas, retornos decrescentes; e, caso seja nulas, retornos constantes de escala. Por exemplo, a unidade II apresenta $\mathrm{u}_{0}=-0,9$ e $\mathrm{v}_{0}=-1,29$; portanto essa unidade, dependendo da situação analisada, poderia aproveitar os retornos crescentes para atingir o porte ótimo.

Por último, resulta interessante ver as metas gerais referentes às unidades ineficientes, sugeridas pelo calculo do Modelo BCC, utilizando-se os preços sombra. Observa-se, na Tabela 5, que as nove unidades ineficientes, se trabalhassem como as outras unidades, poderiam aumentar a produção em 47 alunos formados e em 69 os trabalhos científicos, economizando no uso dos insumos mais de 7,45 milhões de reais com os ativos e outros tantos com a redução de 75 professores. 
Tabela 5: Metas para as Unidades Acadêmicas Ineficientes

\begin{tabular}{|c|c|c|c|c|c|c|c|c|c|c|c|}
\hline \multicolumn{2}{|c|}{ Unidades } & II & IV & VI & VII & IX & $\mathbf{X}$ & XVII & XIX & $\mathbf{X X}$ & $\begin{array}{l}\text { Metas } \\
\text { gerais }\end{array}$ \\
\hline \multirow{3}{*}{ Professores } & Atual & 33 & 59 & 65 & 74 & 33 & 74 & 32 & 30 & 32 & \\
\hline & Metas & 31 & 49 & 38 & 60 & 32 & 59 & 31 & 29 & 30 & \\
\hline & Diferencia & -2 & -10 & -27 & -14 & -1 & -16 & -1 & -1 & -2 & -75 \\
\hline \multirow{3}{*}{$\begin{array}{c}\text { Ativos em } \$ \\
1000\end{array}$} & Atual & 1599,78 & 5147,81 & 5299,05 & 7475,83 & 2610,92 & 7475,83 & 1599,78 & 1599,88 & 1599,78 & \\
\hline & Metas & 1498,43 & 4297,11 & 3062,20 & 5386,62 & 2241,83 & 5909,95 & 1527,73 & 1532,99 & 1499,17 & \\
\hline & Diferencia & $-101,35$ & $-850,70$ & $-2236,85$ & $-2089,21$ & $-369,09$ & $-1565,88$ & $-72,05$ & $-66,89$ & $-100,61$ & $-7452,63$ \\
\hline \multirow{3}{*}{$\begin{array}{c}\text { Alunos } \\
\text { Formados }\end{array}$} & Atual & 78 & 197 & 132 & 234 & 93 & 234 & 90 & 60 & 67 & \\
\hline & Metas & 80 & 197 & 132 & 234 & 104 & 234 & 90 & 81 & 80 & \\
\hline & Diferencia & 2 & 0 & 0 & 0 & 11 & 0 & 0 & 21 & 13 & 47 \\
\hline \multirow{3}{*}{$\begin{array}{l}\text { Produção } \\
\text { Cientifica }\end{array}$} & Atual & 4 & 8 & 68 & 104 & 46 & 16 & 32 & 30 & 32 & \\
\hline & Metas & 34 & 35 & 68 & 104 & 46 & 27 & 32 & 30 & 32 & \\
\hline & Diferencia & 30 & 27 & 0 & 0 & 0 & 11 & 0 & 0 & 0 & 69 \\
\hline
\end{tabular}

Para concluir, é importante ressaltar que a análise e sugestões, decorrentes desta metodologia, estão condicionadas às unidades e variáveis incluídas na pesquisa. Qualquer unidade e/ou variável acrescentada ou excluída da análise modificarão os resultados.

\section{Artigo recebido em 30.11.2004. Aprovado em 27.04.2005.}

\section{REFERÊNCIAS BibLIOGRÁfICAS}

Abel, L. (2000).

Avaliação cruzada da produtividade dos departamentos acadêmicos da UFSC utilizando DEA (Data Envelopment Analysis). Dissertação de Mestrado, Universidade Federal de Santa Catarina, Florianópolis, SC, Brasil.

Banker, R. D.,

Charnes, A., \&

Cooper, W. W. (1984).

Some models for estimating technical and scale inefficiencies in data envelopment analysis. Management Science, 30(9), 1078-1092.
Belloni, J. Á. (2000).

Uma metodologia de avaliação da eficiência produtiva de Universidades Federais Brasileiras. Tese de Doutorado, Departamento de Engenharia de Produção e Sistemas, Universidade Federal de Santa Catarina, Florianópolis, SC, Brasil.

Charnes, A.,

Cooper, W., \&

Rodhers, E. (1978).

Measuring the efficiency of decision marking units. European Journal of Operational Research. 2(6), 429-444. 
Chiang, A. C. (1982).

Matemática para economistas. São

Paulo: McGraw-Hill.

Debreu, G. (1951).

The coefficient of resource utilization. Econometrica. 19(3), 273-292.

Farrell, M. J. (1957).

The measurement of productive efficiency. Journal of the Royal Statistical Society. 120(3), 253-290.

Gonzáles-Araya, M. C. (2003).

Projeções não radiais em regiões fortemente eficientes da fronteira DEA - Algoritmos e aplicações. Tese de Doutorado, Universidade Federal de Rio de Janeiro, Rio de Janeiro, RJ, Brasil.

Holanda, N. (2002).

Introdução à economia: da teoria à prática e da visão micro à macroeconomia (8a ed.). Petrópolis, RJ: Vozes.
Kassai, S. (2002).

Utilização da análise por envoltória de dados (DEA) na análise de demonstrações contábeis. Tese de Doutorado, Faculdade de Economia, Administração e Contabilidade de São Paulo, São Paulo, SP, Brasil.

Lopes, A. L. M. (1998).

Avaliação cruzada da produtividade e qualidade dos departamentos acadêmicos de uma universidade com um modelo de análise envoltória de dados e conjuntos difusos. Tese de Doutorado, Universidade Federal de Santa Catarina, Florianópolis, SC, Brasil.

Varian, H. R. (1997).

Microeconomia: princípios básicos. Rio de Janeiro: Campus.

Vasconcellos, M. A. S., \&

Oliveira, R. G. (1996).

Manual de Microeconomia. São Paulo: Atlas. 